Software copyright

\section{MITI retreat on "piracy"}

\section{Tokyo}

JAPAN's Ministry of International Trade and Industry (MITI) has abandoned its controversial plans to make changes in the laws governing software copyright changes which, in the US view, would have made "worldwide software piracy legal". But plans are going ahead rapidly to strengthen the software industry by setting up a new Y 290 million $(£ 900,000)$ database research centre and by merging software organizations into a single promotional group.

What worries MITI is that Japan's software industry is not growing sufficiently rapidly to enable it to catch up with the West. In the United States and Europe, the explosive growth of the software industry has been fired by the appearance of huge numbers of small entrepreneurial software houses selling software packages wherever a niche can be found for them. Japan is only just entering this stage. Until now, growth has been hampered by big businesses which want to construct their own software or have its specially built for themselves alone, rather than buying a package off the shelf.

To try to boost the industry, MITI called for a new law "more clearly to protect the rights of computer programmers" and to give programmers the right to "allow or refuse the use of software by a third party". At the moment, software rights are provided in an ill-defined way by copyright laws administered by the Ministry of Education, Culture and Science (MESC)'s Cultural Affairs Agency.

But instead of the fifty years' protection given under Japanese copyright law or the seventy-five years given under US law, MITI proposed that only fifteen years be guaranteed - even though some of the early US software still in use is already about that old. What is more, the new law made it possible to require a software developer to sell his software in exchange for a "reasonable payment", whether or not he wanted to sell it, when the sale was "in the public interest" or when use was refused without a "justifiable reason".

Despite strenuous denials from MITI that the plan had been thought up to help Japanese companies to get access to US software technology, the US software industry reacted with fury. Many also felt that the successful lawsuit brought by IBM against Fujitsu and Hitachi - two of Japan's top computer makers - which forced them to pay huge sums in compensation for allegedly copying and reselling IBM software had stirred MITI into proposing such a radical change in the law.

Joining in the US protest was MESC's Cultural Affairs Agency, which refused under any circumstances to yield its control of software copyright to MITI. The combined opposition was eventually sufficient

\section{Hungarian science} intellectual resources. to overwhelm MITI, but not before a remarkable series of semantic squabbles between MESC and MITI over whether software was akin to literature, and thus clearly material that should be protected by copyright, or an "industrial process" which MITI could claim should be dealt with by its patent department.

While MITI's plans for new software laws have reached a dead end, progress has been made this past week in regrouping Japan's database research and development groups. MITI is to use funds from one of its more profitable sidelines running the nation's bicycle races - to draw together the fragmented database industry. Under the bicycle race law, MITI supervises the "fair and safe conduct of all bicycle races" and puts the profits into the improvement of "bicycle and mechanical technology" as well as improvements in "medical care and public hygiene". Although funding databases may be stretching the law's original intentions, Y170 million has been earmarked from the fund as an initial payment to help set up a new institute for database research. A further Y120 million is to be provided by a group of 20 industrial companies, including Mitsubishi, Hitachi, Toshiba, NEC and Fujitsu, that MITI is bringing together along with a number of academic researchers in the universities to form the new group.

The aim is to bring database development up to Western levels. MITI was spurred into action by the result of a survey showing that 679 databases were in use in Japan - ranging from economic statistics to chemical literature - but only 157 (23 per cent) of them had been developed inside the country. Major problems have yet to be overcome, however, to bring together the different groups working on databases. Some databases are already being developed in universities and in the Japan Information Centre of Science and Technology with support from the Science and Technology Agency.

A large database is also under construction in MITI's patent office to store patent information. As it covers a very wide range of fields, it is essential that it be properly integrated into the overall strategy. The problem is the familiar one in Japan of getting competing ministries to work together - particularly difficult in this case because part of MITI's aim in setting up the group was to establish that databases belonged in its territory rather than that of the Ministry of Posts and Telecommunications. The problems are expected to be resolved by the summer and the location and structure of the centre to be agreed upon.

A new industrial grouping is also almost ready for those involved in other areas of software development. Both personal and commercial software are now to be grouped together into one umbrella organization under MITI's aegis to provide a centralized group capable of more "organic" activity. The details of the new organization will be released by MITI at the end of the month.

Alun Anderson

\title{
Making the most of society
}

HUNGARIAN biology must come to terms with the challenge of computers, information technology and systems analysis, Dr Janos Szentagothai, president of the Hungarian Academy of Sciences, told the academy's general assembly last month. The theme of the meeting was the relationship between biology and society - an important subject in a country with a considerable agricultural and food industry and environmental legislation going back to the mid-nineteenth century.

Dr Szentagothai concentrated on three main topics: the academy's role as scientific coordinator in the preparation of socio-economic decisions, basic research of "outstanding future importance" and participation in certain aspects of scientific public life. He stressed the setbacks suffered by Hungarian science as a result of the swingeing cuts in research expenditure two years ago. Even a year's moratorium on spending on new equipment and the servicing of equipment already purchased from abroad had, he said, greatly hindered the utilization of the country's leading

During the meeting, Deputy Premier Jozsef Marjai announced a special government credit of 200 million forints ( $£ 33$ million) for research, in addition to what had been originally planned, most of it to be allocated by the academy for basic research. Nevertheless, Dr Lenart Pal, the general secretary of the academy, urged that other ways of generating research funds must be encouraged, such as the formation of "profitable partnerships and subsidiaries" by research institutes and industry.

It was, however, what Dr Szentagothai called "scientific public life" which provided the major innovation this year. Starting in 1985, the academy's elections are to be "democratized", with multiple candidates for each elective post (president, vice-president, presidium members) and tenure normally restricted to two consecutive five-year terms. A 14-person nominating commission, headed by Professor Bruno Straub, was elected by this year's assembly, and will begin work next March on preparing the necessary lists of candidates.

Vera Rich 